\title{
Consensus recommendations for patient-centered therapy in mild-to-moderate ulcerative colitis: the i Support Therapy-Access to Rapid Treatment (iSTART) approach
}

\author{
Silvio Danese ${ }^{1}$, Rupa Banerjee ${ }^{2}$, JR Fraser Cummings ${ }^{3}$, Iris Dotan ${ }^{4}$, Paulo G Kotze ${ }^{5}$, Rupert Wing Loong Leong ${ }^{6}$, \\ Kristine Paridaens ${ }^{7}$, Laurent Peyrin-Biroulet ${ }^{8}$, Glyn Scott ${ }^{9}$, Gert Van Assche ${ }^{10}$, Jan Wehkamp ${ }^{11}$, \\ Jesús K Yamamoto-Furusho ${ }^{12}$ \\ ${ }^{1}$ Inflammatory Bowel Disease Clinical and Research Unit, Istituto Clinico Humanitas, Milan, Italy, ${ }^{2}$ Inflammatory Bowel Diseases Clinic, Asian \\ Institute of Gastroenterology, Hyderabad, India, ${ }^{3}$ Department of Gastroenterology, Southampton General Hospital, Southampton, UK, ${ }^{4}$ Division \\ of Gastroenterology, Rabin Medical Center, Petah-Tikva, Israel, affiliated with the Sackler Faculty of Medicine, Tel Aviv, Israel, ${ }^{5}$ Colorectal \\ Surgery Unit, Hospital Universitário Cajuru, Pontifical Catholic University of Paraná, Curitiba, Brazil, ${ }^{6}$ Gastroenterology and Liver Services, \\ Concord Hospital, Sydney, Australia, ${ }^{7}$ Ferring Pharmaceuticals, Saint-Prex, Switzerland, ${ }^{8}$ Inserm U954, Department of Gastroenterology, Nancy \\ University Hospital, Lorraine University, Vandoeuvre-les-Nancy, France, ${ }^{9}$ East Kent Hospitals Trust, Canterbury, UK, ${ }^{10}$ UZ Leuven, Leuven, \\ Belgium, ${ }^{11}$ Department of Hepatology, Gastroenterology \& Infectious Diseases, University Hospital Tuebingen, Tübingen, Germany, ${ }^{12}$ IBD Clinic, \\ Department of Gastroenterology, Instituto Nacional de Ciencias Médicas y Nutrición, Mexico City, Mexico
}

Symptomatic ulcerative colitis (UC) can be a chronic, disabling condition. Flares in disease activity are associated with many of the negative impacts of mild-to-moderate UC. Rapid resolution of flares can provide benefits to patients and healthcare systems. i Support Therapy-Access to Rapid Treatment (iSTART) introduces patient-centered care for mild-to-moderate UC. iSTART provides patients with the ability to self-assess symptomology and self-start a short course of second-line treatment when necessary. An international panel of experts produced consensus statements and recommendations. These were informed by evidence from systematic reviews on the epidemiology, mesalazine (5-ASA) treatment, and patient use criteria for second-line therapy in UC. Optimized 5-ASA is the first-line treatment in all clinical guidelines, but may not be sufficient to induce remission in all patients. Corticosteroids should be prescribed as second-line therapy when needed, with budesonide $\mathrm{MMX}^{\circledR}$ being a preferred steroid option. Active involvement of suitable patients in management of UC flares has the potential to improve therapy, with patients able to show good accuracy for flare self-assessment using validated tools. There is a place in the UC treatment pathway for an approach such as iSTART, which has the potential to provide patient, clinical and economic benefits. (Intest Res 2018;16:522-528)

Key Words: Colitis, ulcerative; Consensus guidelines; Mesalazine; Corticosteroids; Patient reported outcome measures

\section{INTRODUCTION}

Continued improvements in the management of UC are need-

Received May 23, 2018. Revised August 16, 2018

Accepted August 28, 2018.

Correspondence to Silvio Danese, Inflammatory Bowel Disease Clinical and Research Unit, Istituto Clinico Humanitas, Via Manzoni 56, 20089 Rozano, Milan, Italy. Tel: +39-2-82244771, Fax: +39-2-82244590, E-mail: sdanese@ hotmail.com ed to enable the most efficacious and efficient treatment possible for this disease. This is particularly important for UC of a mild-to-moderate severity, as the prevalence and incidence of UC is increasing worldwide, ${ }^{1-3}$ and a mild-to-moderate severity is most common at diagnosis. ${ }^{4-9}$ The treatment of this chronic disease is primarily aimed to induce and then maintain remission in the long-term, ${ }^{10-12}$ with remission normally defined as a normal bowel frequency ( $\leq 3$ per day), absence of rectal 
bleeding and normal mucosal appearance on endoscopy. ${ }^{10,13}$ Even when remission is achieved, the majority of the patients experience a relapse at some point. ${ }^{14,15}$ Rapid treatment and resolution of relapses is a key treatment requirement as active disease has many negative impacts for patients, healthcare systems and society. Active UC is associated with reduced quality of life (QoL) for patients, ${ }^{16-19}$ higher utilization of healthcare resources, ${ }^{20-22}$ and personal costs to patients, such as time off work and reduced productivity. ${ }^{23,24}$ Therefore, improvements to the treatment of disease flares in mild-to-moderate UC patients is beneficial.

\section{iSTART}

i Support Therapy-Access to Rapid Treatment (iSTART) is an initiative to improve patient-centered management to UC. The iSTART initiative gives mild-to-moderate UC patients (selected by their physician) the ability to self-assess UC symptomology, increase dosing of first-line therapy to an optimized level and self-start second-line treatment. iSTART is designed to fit within the framework supplied by published treatment guidelines. Clinicians should select only the most appropriate patients, including, for example: those at a high risk of relapse, those with limited access to healthcare services, those who take an active interest in their disease and its treatment, and those at a low risk of Clostridium difficile infection. Under iSTART, patients on optimized first-line therapy will be provided with training on how to identify a symptomatic flare, and provided with a prescription for second-line treatment for use when optimized first-line treatment is insufficient to maintain remission. If the patient experiences a flare they will self-start a short course of second-line therapy whilst contacting their clinic who will manage any ongoing treatment. The short course prescribed ensures that patients cannot self-medicate unsupervised and iSTART emphasizes that clinicians must be informed if the prescription is used to allow long-term changes in disease management.

The iSTART approach will allow for the fast treatment of flares, producing benefits for patients and healthcare systems. For patients, iSTART aims to improve day-to-day QoL and to create a sense of empowerment over their disease. Empowering patients to reliability self-assess a UC flare would allow faster commencement of second-line therapy, reducing the duration of active disease and associated damage and reduced patient QoL. Furthermore, this would reduce the number of patients seeking emergency healthcare, decreasing the clinical and healthcare burden of mild-to-moderate UC treatment. iSTART will also provide additional support to patients with limited access to their physician, such as those whose location or distance from their physician leave them unable to access timely treatment, and allow them access to rapid care that is currently unavailable to them.

iSTART will need to be adapted into an appropriate form to fit around different healthcare systems and local populations. This consensus paper provides a general outline of the principles of iSTART and the scientific evidence behind them from the physicians' perspective. For future implementation, consideration of local factors in areas where iSTART is to be implemented will be necessary. In addition, patient involvement to guide the implementation of iSTART to match patients' requirements and treatment goals is necessary; but these considerations are better addressed at a local level to match the cultural situation and healthcare systems in a particular area.

\section{CONSENSUS METHODS}

An expert panel of gastroenterologists, including clinicians from Europe, Asia, Australia, and Latin America were assembled in Amsterdam to generate consensus on patient-centered second-line therapy in the form of the iSTART initiative. Supporting evidence was brought together from 3 literature reviews reflecting the global epidemiology of UC; mesalazine (5-ASA) treatment and its failure; second-line therapy and validated tools suitable for self-led patient assessment. Searches were performed using the PubMed, Embase, Cochrane Library and clinicaltrials.gov platforms. Advisors voted on draft consensus statements based on the evidence-based reviews and in line with current guidelines for mild-to-moderate UC. Advisors voted whether they "strongly agree," "agree" or "disagree/uncertain" for each statement. A statement was passed if $\geq 75 \%$ of the panel agreed/strongly agreed with a statement; if consensus was not reached, statements were revised via group discussion. The agreed consensus was then used as the basis to produce a series of recommendations, which were voted on using the same methodology. A full list of consensus statements and the literature supporting them was compiled (Supplementary Material 1).

\section{CURRENT TREATMENT REGIMEN}

The current treatment protocol for mild-to-moderate UC is well established and is outlined in all major guidelines on 
UC. ${ }^{10-12}$ 5-ASA is the recommended first-line therapy for the induction and maintenance of remission in mild-to-moderate UC. ${ }^{10-12}$ Although exact regimens vary depending on disease extent, the recommendations for the induction of remission are combination therapy consisting of rectal $(1 \mathrm{~g} /$ day $)$ and high dose oral 5-ASA (2-4 g/day)..$^{10-12}$ This optimized 5-ASA therapy is designed to induce remission quickly and effectively; such regimens are able to induce remission in $50 \%$ to $70 \%$ of patients. ${ }^{25}$

For patients that do not respond sufficiently to optimized 5-ASA, oral or rectal corticosteroids are the recommended second-line treatment in all major guidelines. ${ }^{10-12} \mathrm{~A}$ key consideration in corticosteroid treatment is the adverse event profile often associated with these treatments, especially when a systemic mode of delivery is used, as corticosteroids are associated with a number of well-known side effects, such as adrenal suppression. ${ }^{26,27}$ To overcome the drawbacks of corticosteroid therapy, "second-generation" steroids have been developed, such as budesonide and more advanced formulations. ${ }^{26,27}$ Oral budesonide has a high first-pass metabolism which significantly reduces systemic exposure and it has been formulated for UC using MMX ${ }^{\circledR}$ Multimatrix technology to provide a targeted colonic delivery. ${ }^{26,27}$ Budesonide $\mathrm{MMX}^{\circledR}$ has shown high levels of efficacy in clinical trials, ${ }^{28,29}$ and equally as importantly no difference in adverse events to placebo (RR, 0.85 ; 95\% CI, 0.53-1.38). ${ }^{28}$ These characteristics make budesonide $\mathrm{MMX}^{\circledR}$ a corticosteroid that has a profile suited to an initiative such as iSTART.

\section{PATIENT-CENTERED TREATMENT IN UC}

For an initiative such as iSTART to be successful requires reliable methods for patients to self-assess their condition. A number of simple indices for disease evaluation in UC have been developed that could be used by patients to monitor their disease. However, to have confidence in the use of such an index in clinical practice requires its validation. Three such validated indices that have been identified: the PRO2, the patient-reported UC activity index (PRUCSI) and the mobile health index for UC (mHI-UC). ${ }^{30-32}$ The PRO2 uses 2 indicators, stool frequency and rectal bleeding, and has an area under the receiver operating characteristic curve (AUC) of 0.90 in a validation cohort using an endoscopy score of $\leq 1$ to define remission (AUC was 0.80 when using a score of 0 to define remission). ${ }^{30}$ The PRUCSI uses the 6-point Mayo score with the addition of patient-defined "general well-being." ${ }^{\text {"31 }}$ The
PRUCSI has a validated AUC of 0.91 , with a sensitivity of $78 \%$ and specificity of $84 \% .^{31}$ The $\mathrm{mHI}-\mathrm{UC}$ incorporates patient-reported measurements derived from UC disease activity indices. ${ }^{32}$ The mHI-UC uses 4 questions covering stool frequency, rectal bleeding, abdominal pain and overall well-being within a complex scoring system to define flares. ${ }^{32}$ The $\mathrm{mHI}-\mathrm{UC}$ has reported an AUC of over 0.91 , with a sensitivity of $72 \%$ and a specificity of $90 \% .^{32}$ AUC values of 0.8 or higher are accepted to show a good predictive value, and values of 0.9 or greater show an excellent predictive value. These results show that these 3 indices all have a strong power for identifying flares and the potential to be used within iSTART.

Evidence of the benefits of patient-centered care in UC comes from a number of studies. In Denmark, a self-care web portal increased adherence in a validation group of 333 UC patients, and reduced the duration of relapses (18 days vs. 77 days for control cohort) ${ }^{33-35}$ The UC home telemanagement system (UC HAT), from the United States, used self-reporting of symptoms through 14 computerized questions to produce treatment recommendations. ${ }^{36,37}$ A clinical trial of UC HAT found that it improved patient QoL compared to standard care. ${ }^{37} \mathrm{~A}$ UK study used individualized patient-directed management plans to trigger additional treatment when a relapse occurred. ${ }^{38}$ Compared to controls, this intervention caused a non-significant reduction in the average number of relapses (1.53 vs. 1.93), a significant reduction in time to treatment of a relapse (14.8 hours vs. 49.6 hours, $P<0.0001$ ), a non-significant decrease in the length of flares and a significant decrease in average number of general practitioner and hospital visits $(P<0.0001){ }^{38}$ These studies show the potential of patient-centered management within UC, and the advantages for rapid treatment of flares for patients, clinicians and health systems.

\section{CONCLUSIONS}

Active disease in mild-to-moderate UC causes a significant health burden that can have a great impact on the daily life and QoL of those affected. The burden of disease in this group is particularly important with the increasing global incidence of UC and mild-to-moderate disease being the most common at diagnosis. There is therefore the potential for iSTART to have an impact on improving treatment in this large and important group of patients.

Although optimized 5-ASA treatment is an effective firstline treatment, it is not sufficient to control active UC in all patients. Steroids are the accepted second-line treatment and oral 
budesonide $\mathrm{MMX}^{\circledR}$ should be considered as a preferred corticosteroid option for mild-to-moderate disease, due to its high efficacy and low incidence of steroid-related adverse events. Timely and appropriate access to second-line therapy is necessary to minimize the impact of active UC on both healthcare systems and patients.

The potential for patient-centered care in UC has been demonstrated in a number of studies. However, these have also shown that clear guidance and definitions are required for accurate self-reporting. A small number of validated patient-reported outcome measures for disease activity in UC have been developed. The use of these indices within iSTART should allow an accurate and rapid initiation of treatment for a flare. Whilst there are potential benefits to all patients from iSTART, clinicians should select only the most appropriate patients. iSTART also makes clear to patients that upon experiencing a flare, they must contact their clinicians to allow their ongoing disease management to be reassessed. The recommendations of the expert panel are shown below, and these outline the basic principles of iSTART as have been summarized above.

\section{RECOMMENDATIONS}

Recommendation 1: In line with current treatment guidelines, it is recommended that the primary focus of treatment in UC is the rapid induction of remission followed by maintenance of this remission in the long-term.

(strongly agreed $90.0 \%$; agreed $10.0 \%$; disagreed $0.0 \%$ : CONSENSUS REACHED)

Recommendation 2: It is recommended that in the event of a flare, patients with mild-to-moderate UC should be treated as soon as possible to get them back into remission:

- Optimization of 5-ASA therapy to a high dose oral and/or rectal therapy should occur before any other therapy is considered

- Rapid access to second-line therapies is important due to flares causing a clinical and economic impact that can be reduced by fast treatment

(strongly agreed $50.0 \%$; agreed $40.0 \%$; disagreed $10.0 \%$ : CONSENSUS REACHED)

Recommendation 3: It is recommended that treatment for mild-to-moderate UC should begin with optimized 5-ASA therapy: high dose oral and/or at least $1 \mathrm{~g} /$ day topical, in line with current treatment guidelines.

(strongly agreed 81.8\%; agreed 9.1\%; disagreed 9.1\%: CON-

\section{SENSUS REACHED)}

Recommendation 4: It is recommended that oral budesonide $\mathrm{MMX}^{\circledR}$ is a preferred corticosteroid in patients with a mild-tomoderate flare:

- In line with previous recommendations, this therapy should be initiated as soon as possible by patients who experience a flare that does not respond to optimized 5-ASA

(strongly agreed $81.8 \%$; agreed $18.2 \%$; disagreed $0.0 \%$ : CONSENSUS REACHED)

Recommendation 5: It is recommended that patients with mild-to-moderate UC should have active involvement in their disease management and therapy to enable rapid treatment:

- Patient-reported outcome monitoring can rapidly identify a flare and give opportunities to swiftly initiate therapy prior to seeing a clinician

- This is particularly important for high-risk individuals (e.g., those with frequent flares, or those with new diagnoses and additional risk factors, or any patient deemed high risk by treating physician) or those in locations or health care systems with difficulties in quickly accessing healthcare

- Good communication between physician and patient is vital for this to work

(strongly agreed 60.0\%; agreed 30.0\%; disagreed 10.0\%: CONSENSUS REACHED)

Recommendation 6: It is recommended that patient-reported outcome measures:

- Have the potential to be used for flare identification

- Can be used by patients to monitor disease activity

- Have the potential to be used by patients to initiate treatment of flares

- Should be initiated as a management tool for suitable patients

(strongly agreed $72.7 \%$; agreed $27.3 \%$; disagreed $0.0 \%$ : CONSENSUS REACHED)

Recommendation 7: It is recommended that PRO2 and PRUCSI are appropriate patient-reported indices for self-assessment, as they are simple, validated and have a strong discriminatory power for flares:

- The PRO2 or PRUCSI can be used by patients to assess disease by monitoring changes in stool frequency and rectal bleeding

- An increase in PRUCSI or PRO2 score of $>1$ over a 3-5 
days could be used to identify a flare

(strongly agreed 63.6\%; agreed 27.4\%; disagreed 9.0\%: CONSENSUS REACHED)

Recommendation 8: The group recommends that a program such as iSTART could provide improved treatment of flares in UC patients.

(strongly agreed $72.7 \%$; agreed $27.3 \%$; disagreed $0.0 \%$ : CONSENSUS REACHED)

\section{FINANCIAL SUPPORT}

Sponsorship and article processing charges for this study were funded by Ferring. Ferring provided funding to Strategen Limited to undertake the systematic reviews and to provide editorial assistance in the preparation of this manuscript.

\section{CONFLICT OF INTEREST}

Silvio Danese has served as speaker, consultant and advisory board member for AbbVie, Ferring, Hospira, Johnson \& Johnson, Merck, MSD, Takeda, Mundipharma, Pfizer Inc, TiGenix, UCB Pharma, Vifor Pharma, Biogen, Celgene, Allergan, Celltrion, Sandoz and Boehringer Ingelheim.

Rupa Banerjee has served as member of advisory boards, speaker and KOL for Janssen, Takeda, Ferring, Cipla, Cadila, Abbott and Menarini, India.

Fraser Cummings has received consulting fees from MSD, AbbVie, Janssen, Ferring, Vifor, Pharmacosmos, Hospira, Celltrion, Takeda, Sandoz, Biogen, Shield Therapeutics, Dr Falk and NAPP and lecture fees from Merck, AbbVie, Takeda, Janssen, Takeda, Mundipharma, Pfizer, Pharmacosmos, Shield Therapeutics, and Vifor.

Iris Dotan has served on advisory boards for Janssen, $\mathrm{Ab}$ bVie, Takeda, Genentech, Pfizer, Ferring, Rafa Laboratories, Given Imaging, Protalix, Medison, Celgene; has received Speakers Bureaus from Janssen, AbbVie, Takeda, Genetech, Pfizer, Ferring, Falk Pharma, MSD, Given Imaging; and has received research funding from the Leona M and Harry B Helmsley Charitable Trust, Janssen, AbbVie.

Paulo G Kotze has received honoraria from AbbVie, Ferring, Janssen, Pfizer and Takeda as a speaker and member of advisory boards.

Rupert W Leong has served on advisory boards for Aspen, AbbVie, Ferring, Hospira, Janssen, MSD, Pfizer, Takeda and has received research funding from Shire, Janssen, Endochoice and the Gastroenterological Society of Australia.

Kristine Paridaens is an employee of Ferring Pharmaceuticals.

Laurent Peyrin-Biroulet has received consulting fees from AbbVie, MSD, Janssen, Genentech, Mitsubishi, Ferring, Norgine, Shire, Tillots, Vifor, Pharmacosmos, Pilège, BMS, UCB-pharma, Hospira, Celltrion, Takeda, Boehringer-Ingelheim, Lilly, Pfizer, HAC-Pharma, Amgen, Sandoz, Celgene, Biogen, Samsung Bioepis and lecture fees from Merck, AbbVie, Takeda, Janssen, Ferring, Norgine, Tillots, Vifor, Therakos, Mitsubishi, HAC-pharma.

Glyn Scott has served on advisory boards for AbbVie and Ferring and as a speaker for Ferring.

Gert Van Assche has been a consultant for MSD, Takeda, Genentech/Roche, AbbVie, Pfizer, Janssen and Ferring. He has received payment for lecturing at continuing medical education events from AbbVie, Takeda, MSD, Janssen and Ferring. He receives research funding from AbbVie, Pfizer, The Broad Foundation and The Fonds voor Wetenschappelijk Onderzoek Vlaanderen.

Jan Wehkamp has served as a consultant for MSD, Takeda, Novartis, Shire, AbbVie, Ardeypharm, Pfizer, Biogen, Johnson and Ferring, and received payment for lecturing at continuing medical education events from the Falk Foundation, AbbVie, Takeda, MSD, Johnson, Roche, Ferring, Novartis and Shire. He has received research funding from the Deutsche Forschungsgemeinschaft and the European Union (ERC), and received third-party research funding for carrying out clinical trials on behalf of Amgen, Novartis, Falk Pharma, and AbbVie. He is a member of the board of Defensin Therapeutics. He serves as president of the Alfred Nissle society and is also the chair of the German society of mucosal immunology and microbiome (DGIM).

Jesús K Yamamoto-Furusho has received honoraria from AbbVie, Ferring, Takeda, Janssen, UCB, Almirall, Pfizer, Novartis, Farmasa and Danone as speaker, key opinion leader and member of advisory boards at national and international levels. He is President of the Pan American Crohn's and Colitis Organization (PANCCO).

\section{AUTHOR CONTRIBUTION}

Conceptualization: all authors. Methodology: all authors. Formal analysis: Not applicable. Funding acquisition: S.D. Project administration: S.D. Visualization: all authors. Writing - original draft: S.D. Writing - review and editing: all authors. Approval of final manuscript: all authors. 


\section{ACKNOWLEDGEMENTS}

Strategen Limited undertook the systematic reviews and provided editorial assistance in the preparation of this manuscript. Ferring had the opportunity to review and comment on the completed manuscript but final editorial control rested fully with the authors. All named authors meet the International Committee of Medical Journal Editors (ICMJE) criteria for authorship for this manuscript, take responsibility for the integrity of the work as a whole, and have given final approval to the version to be published.

\section{REFERENCES}

1. Molodecky NA, Soon IS, Rabi DM, et al. Increasing incidence and prevalence of the inflammatory bowel diseases with time, based on systematic review. Gastroenterology 2012;142:46-54.e42.

2. M'Koma AE. Inflammatory bowel disease: an expanding global health problem. Clin Med Insights Gastroenterol 2013;6:33-47.

3. Prideaux L, Kamm MA, De Cruz PP, Chan FK, Ng SC. Inflammatory bowel disease in Asia: a systematic review. J Gastroenterol Hepatol 2012;27:1266-1280.

4. Lok KH, Hung HG, Ng CH, et al. Epidemiology and clinical characteristics of ulcerative colitis in Chinese population: experience from a single center in Hong Kong. J Gastroenterol Hepatol 2008; 23:406-410.

5. Nuij VJ, Zelinkova Z, Rijk MC, et al. Phenotype of inflammatory bowel disease at diagnosis in the Netherlands: a population-based inception cohort study (the Delta Cohort). Inflamm Bowel Dis 2013;19:2215-2222.

6. Yazdanbod A, Farzaneh E, Pourfarzi F, et al. Epidemiologic profile and clinical characteristics of ulcerative colitis in northwest of Iran: a 10-year review. Trop Gastroenterol 2010;31:308-311.

7. Gheorghe C, Pascu O, Gheorghe L, et al. Epidemiology of inflammatory bowel disease in adults who refer to gastroenterology care in Romania: a multicenter study. Eur J Gastroenterol Hepatol 2004;16:1153-1159.

8. Ling KL, Ooi CJ, Luman W, Cheong WK, Choen FS, Ng HS. Clinical characteristics of ulcerative colitis in Singapore, a multiracial city-state. J Clin Gastroenterol 2002;35:144-148.

9. Niriella MA, De Silva AP, Dayaratne AH, et al. Prevalence of inflammatory bowel disease in two districts of Sri Lanka: a hospital based survey. BMC Gastroenterol 2010;10:32.

10. Bressler B, Marshall JK, Bernstein CN, et al. Clinical practice guidelines for the medical management of nonhospitalized ulcerative colitis: the Toronto consensus. Gastroenterology 2015;148:10351058.e3.
11. Harbord M, Eliakim R, Bettenworth D, et al. Third European evidence-based consensus on diagnosis and management of ulcerative colitis. Part 2: current management. J Crohns Colitis 2017; 11:769-784.

12. Kornbluth A, Sachar DB; Practice Parameters Committee of the American College of Gastroenterology. Ulcerative colitis practice guidelines in adults: American College of Gastroenterology, Practice Parameters Committee. Am J Gastroenterol 2010;105:501-523.

13. Magro F, Gionchetti P, Eliakim R, et al. Third European evidencebased consensus on diagnosis and management of ulcerative colitis. Part 1: definitions, diagnosis, extra-intestinal manifestations, pregnancy, cancer surveillance, surgery, and ileo-anal pouch disorders. J Crohns Colitis 2017;11:649-670.

14. Portela F, Magro F, Lago P, et al. Ulcerative colitis in a Southern European country: a national perspective. Inflamm Bowel Dis 2010; 16:822-829.

15. Sjöberg D, Holmström T, Larsson M, et al. Incidence and natural history of ulcerative colitis in the Uppsala Region of Sweden 20052009: results from the IBD cohort of the Uppsala Region (ICURE). J Crohns Colitis 2013;7:e351-e357. doi: 10.1016/j.crohns.2013.02.006.

16. Huppertz-Hauss G, Lie Høivik M, Jelsness-Jørgensen LP, et al. Healthrelated quality of life in patients with inflammatory bowel disease 20 years after diagnosis: results from the IBSEN study. Inflamm Bowel Dis 2016;22:1679-1687.

17. Theede K, Kiszka-Kanowitz M, Nordgaard-Lassen I, Mertz Nielsen A. The impact of endoscopic inflammation and mucosal healing on health-related quality of life in ulcerative colitis patients. J Crohns Colitis 2015;9:625-632.

18. Alcalá MJ, Casellas F, Fontanet G, Prieto L, Malagelada JR. Shortened questionnaire on quality of life for inflammatory bowel disease. Inflamm Bowel Dis 2004;10:383-391.

19. Romberg-Camps MJ, Bol Y, Dagnelie PC, et al. Fatigue and healthrelated quality of life in inflammatory bowel disease: results from a population-based study in the Netherlands: the IBD-South Limburg cohort. Inflamm Bowel Dis 2010;16:2137-2147.

20. Bodger K, Yen L, Szende A, et al. Medical resource utilization and associated costs in patients with ulcerative colitis in the UK: a chart review analysis. Eur J Gastroenterol Hepatol 2014;26:213-221.

21. de Boer AG, Sprangers MA, Bartelsman JF, de Haes HC. Predictors of health care utilization in patients with inflammatory bowel disease: a longitudinal study. Eur J Gastroenterol Hepatol 1998; 10:783-789.

22. Sulz MC, Siebert U, Arvandi M, et al. Predictors for hospitalization and outpatient visits in patients with inflammatory bowel disease: results from the Swiss Inflammatory Bowel Disease Cohort Study. Eur J Gastroenterol Hepatol 2013;25:790-797. 
23. Siebert U, Wurm J, Gothe RM, et al. Predictors of temporary and permanent work disability in patients with inflammatory bowel disease: results of the swiss inflammatory bowel disease cohort study. Inflamm Bowel Dis 2013;19:847-855.

24. Ramos A, Calvet X, Sicilia B, et al. IBD-related work disability in the community: prevalence, severity and predictive factors. A crosssectional study. United European Gastroenterol J 2015;3:335-342.

25. Wang Y, Parker CE, Bhanji T, Feagan BG, MacDonald JK. Oral 5-aminosalicylic acid for induction of remission in ulcerative colitis. Cochrane Database Syst Rev 2016;4:CD000543. doi: 10.1002/ 14651858.CD000543.pub4.

26. Lichtenstein GR. Budesonide multi-matrix for the treatment of patients with ulcerative colitis. Dig Dis Sci 2016;61:358-370.

27. Abdalla MI, Herfarth H. Budesonide for the treatment of ulcerative colitis. Expert Opin Pharmacother 2016;17:1549-1559.

28. Sherlock ME, MacDonald JK, Griffiths AM, Steinhart AH, Seow $\mathrm{CH}$. Oral budesonide for induction of remission in ulcerative colitis. Cochrane Database Syst Rev 2015;(10):CD007698. doi: 10.1002/ 14651858.CD007698.pub3.

29. Sandborn WJ, Danese S, D'Haens G, et al. Induction of clinical and colonoscopic remission of mild-to-moderate ulcerative colitis with budesonide MMX 9 mg: pooled analysis of two phase 3 studies. Aliment Pharmacol Ther 2015;41:409-418.

30. Jairath V, Khanna R, Zou GY, et al. Development of interim patientreported outcome measures for the assessment of ulcerative colitis disease activity in clinical trials. Aliment Pharmacol Ther 2015; 42:1200-1210
31. Bewtra M, Brensinger CM, Tomov VT, et al. An optimized patientreported ulcerative colitis disease activity measure derived from the Mayo score and the simple clinical colitis activity index. Inflamm Bowel Dis 2014;20:1070-1078.

32. Van Deen WK, van der Meulen-de Jong AE, Parekh NK, et al. Development and validation of an inflammatory bowel diseases monitoring index for use with mobile health technologies. Clin Gastroenterol Hepatol 2016;14:1742-1750.e7.

33. Elkjaer M. E-health: web-guided therapy and disease self-management in ulcerative colitis. Impact on disease outcome, quality of life and compliance. Dan Med J 2012;59:B4478.

34. Elkjaer M, Burisch J, Avnstrøm S, Lynge E, Munkholm P. Development of a web-based concept for patients with ulcerative colitis and 5-aminosalicylic acid treatment. Eur J Gastroenterol Hepatol 2010;22:695-704.

35. Elkjaer M, Shuhaibar M, Burisch J, et al. E-health empowers patients with ulcerative colitis: a randomised controlled trial of the web-guided 'Constant-care' approach. Gut 2010;59:1652-1661.

36. Cross RK, Cheevers N, Finkelstein J. Home telemanagement for patients with ulcerative colitis (UC HAT). Dig Dis Sci 2009;54:24632472.

37. Cross RK, Cheevers N, Rustgi A, Langenberg P, Finkelstein J. Randomized, controlled trial of home telemanagement in patients with ulcerative colitis (UC HAT). Inflamm Bowel Dis 2012;18:1018-1025.

38. Robinson A, Thompson DG, Wilkin D, Roberts C; Northwest Gastrointestinal Research Group. Guided self-management and patient-directed follow-up of ulcerative colitis: a randomised trial. Lancet 2001;358:976-981. 


\section{CONSENSUS STATEMENTS}

\section{Epidemiology}

Statement 1: The global incidence and prevalence of UC is rising (grade B) (strongly agreed 90.0\%; agreed 10.0\%; disagreed 0.0\%: CONSENSUS REACHED)

The incidence and prevalence of UC has been documented in a number of systematic reviews, ${ }^{1-3}$ with numerous primary epidemiological studies providing supporting evidence. There has been a rapid increase in the incidence and prevalence of UC since the mid-20th century across many countries. ${ }^{1,2}$ The EpiCom study reported incidence rates in Europe of 4 to 19 per 100,000 in 2010, with similar rates found in Canada, ${ }^{1,5,6}$ and Australia; ${ }^{1,7}$ whereas Asia and Latin America have lower rates of around 1 to 5 per 100,000. ${ }^{1,7,8}$ The prevalence of UC in Europe, Canada and Australia has been estimated at 100 to 290 per 100,000. ${ }^{1,5,6,9,10}$ Prevalence is lower across Asia and Latin America at 10 to 60 per 100,000.,

Statement 2: Mild-to-moderate disease is most prevalent at diagnosis (grade B)

(strongly agreed 100\%; statement revised and CONSENSUS REACHED via discussion)

Despite differences classification scales, the proportion classified with mild-to-moderate UC was 70\% to $95 \%$ at diagnosis and therefore is the predominant form of the disease. ${ }^{13-18}$

Statement 3: An intermittent-relapsing course is most common (grade B)

(strongly agreed 60.0\%; agreed 40.0\%; disagreed 0.0\%: CONSENSUS REACHED)

Four disease courses have been described in UC: single relapse followed by sustained remission; intermittent relapses separated by remission periods; chronic active; and fulminant. The most common form of UC is an intermittent-relapsing course, affecting $40 \%$ to $60 \%$ of patients. ${ }^{19-22}$

Statement 4: Episodes of disease activity (in contrast to remission periods) are associated with a significantly decreased patient quality of life, a significant impact on daily life, and increased healthcare costs and burden (grade C) (strongly agreed 100\%; statement revised and CONSENSUS REACHED via discussion)

A key consequence of active disease is an increased number and frequency of symptoms. ${ }^{23}$ Symptoms that are more common in active UC compared to remission include fatigue ${ }^{24,25}$ pain, ${ }^{26}$ extraintestinal manifestations (EIMs), ${ }^{27}$ and fecal incontinence. ${ }^{28}$ Active disease has also been associated with depression, ${ }^{29-31}$ anxiety, ${ }^{30,31}$ and sleep disruption. ${ }^{32,33}$ Symptoms disrupt daily life for $94 \%$ of patients during a flare, ${ }^{34}$ leading to a reduced quality of life during active disease. ${ }^{35-38}$ Quality of life has been found to correlate the frequency of symptoms, ${ }^{39}$ and the number of relapses experienced. ${ }^{40,41}$ Studies from many countries have shown that EQ5D is significantly reduced during active compared to inactive disease. ${ }^{42-44}$ Relapses in UC are associated with higher rates of physician, emergency and outpatient visits, ${ }^{45-47}$ which leads to increased healthcare costs. ${ }^{43,45,48}$ Furthermore, active UC also leads to increased absences from work, ${ }^{49}$ and a higher likelihood of claiming a disability pension. ${ }^{49,50}$ 
Statement 5: At any time, $25 \%$ of patients have active disease with symptoms that may require additional therapeutic intervention (grade B) (strongly agreed 100\%; statement revised and CONSENSUS REACHED via discussion)

The largest available, recent dataset (EpiCom study) shows that $70 \%$ to $74 \%$ of patient were in remission at any time, with the remainder showing symptomatic disease. ${ }^{51}$ These figures are supported by a Canadian systematic review that found $75 \%$ to $90 \%$ of patients were in remission at any time. ${ }^{52}$

Statement 6: Patients within 1 year of diagnosis have the highest rate of relapse, with $\sim 50 \%$ having symptomatically active disease that may require additional therapeutic intervention (grade B)

(strongly agreed 100\%; statement revised and CONSENSUS REACHED via discussion)

Longitudinal epidemiological studies have shown a gradual decrease in the rate of relapse over time after diagnosis. ${ }^{53,54}$ Similar data are seen for 5-ASA treated patients, ${ }^{55-58}$ and a longitudinal investigation of 5-ASA treatment clearly demonstrated the highest risk of relapse during the first 2 to 3 years after diagnosis. ${ }^{56,57}$ Around $50 \%$ of newly diagnosed patients have active disease at any time. ${ }^{51,59-61}$ The EpiCom study found that $89 \%$ of patients had active disease at diagnosis, which dropped to $59 \%$ after 3 months and $28 \%$ after 1 year. ${ }^{51}$

Statement 7: Rate of spontaneous remission is low; $<10 \%$ when using a strict definition of clinical and endoscopic remission (grade B) (strongly agreed 30.0\%; agreed 70.0\%; disagreed 0.0\%: CONSENSUS REACHED)

The placebo arms in clinical trials give the best available estimate as to the effects of delayed treatment on disease activity. The rate of remission varies depending on the definition used, but overall these trials have shown a low rate of spontaneous remission in UC of around $17 \%{ }^{62}$ However, the rate of remission in placebo-treated patients is lower $(<10 \%)$ when a stricter definition of remission is used that incorporates clinical and endoscopic definitions. ${ }^{63,64}$

Statement 8: During the average year, 70\% of patients with UC will experience at least 1 relapse (grade C) (strongly agreed 100\%; statement revised and CONSENSUS REACHED via discussion)

Around $30 \%$ of patients experience no relapses in a year and therefore around 70\% experience at least 1 relapse. . $3,45,65,66^{-6}$

Statement 9: The rate of relapse is reduced by $\sim 25 \%$ in the year following no flare compared to a year following a flare (grade C) (strongly agreed 100\%; statement revised and CONSENSUS REACHED via discussion)

Only a small number of studies have attempted to quantify the difference in risk between patients who have had a flare and those who have not in the previous year. In a study from Norway, $30 \%$ of patients relapsed after a period of remission compared to $63 \%$ after a period of active disease, a $52 \%$ reduction $(P<0.001) .{ }^{60}$ An Iranian study reported a $20 \%$ reduction in relapse rate for all patients compared to those with a previous relapse.$^{65} \mathrm{~A}$ Korean cohort study showed a $46.3 \%$ reduction in the relapse rate for patients who showed mucosal healing compared to those who did not $(36.3 \%$ vs. $19.5 \%, P=0.006) .{ }^{67}$ These limited data were combined with the panel's expert opinion to estimate risk reduction at $25 \%$.

Statement 10: Clinicians are not fully aware of the number of relapses patients experience (grade C) (strongly agreed $70.0 \%$; agreed $30.0 \%$; disagreed $0.0 \%$ : CONSENSUS REACHED)

A survey of patients and clinicians found that physicians and nurses had a lower estimate of the number of relapses for each patient compared to the numbers self-reported; patients reported a mean of 5.5 flares over a year, versus estimates of 3.4 by doctors 
and 3.8 by nurses ${ }^{68}$ Patients reported discussing only an average of 4.2 flares with their primary healthcare professional (HCP), which implies the majority of this perception gap occurs due to non-disclosure of flares by patients to HCPs. ${ }^{68}$

\section{First-Line Treatment and Treatment Failure}

Statement 11: Optimized 5-ASA is the accepted first-line treatment for mild-to-moderate UC across all treatment guidelines (grade A) (strongly agreed 90.0\%; agreed 10.0\%; disagreed 0.0\%: CONSENSUS REACHED)

The treatment guidelines reviewed were those of the European Crohn's and Colitis Organisation (ECCO), ${ }^{69,70}$ the Canadian Association of Gastroenterology (CAG), ${ }^{71}$ the World Gastroenterology Organisation, ${ }^{72}$ the American Gastroenterology Association, ${ }^{73}$ the American College of Gastroenterology, ${ }^{74}$ and the Pan American Crohn's and Colitis Organization. ${ }^{75}$

Statement 12: Optimized 5-ASA treatment is sufficient to achieve remission in 50\% to 70\% of patients (grade B) (strongly agreed 100\%; statement revised and CONSENSUS REACHED via discussion)

Optimized 5-ASA therapy is a high dose oral regimen combined with a topical 5-ASA regimen designed to induce remission quickly and effectively. A recent Cochrane Review reported that high dose regimens of 5-ASA are able to induce remission in between $50 \%$ and $70 \%$ of UC patients. ${ }^{62}$

Statement 13: 5-ASA treatment failure can be defined as the inability to achieve steroid-free remission with an optimized regimen of high dose oral and/or rectal 5-ASA (grade B)

(strongly agreed 81.8\%; agreed 0.0\%; disagreed 18.2\%: CONSENSUS REACHED)

Statement 14: Optimized 5-ASA treatment (high dose oral and/or rectal) can be considered insufficient and additional treatment is required when $5-A S A$ is unable to maintain steroid-free remission (grade $B$ ) (strongly agreed 45.5\%; agreed 45.5\%; disagreed 9.0\%: CONSENSUS REACHED)

Treatment failure is often not explicitly defined. Guidelines define UC treatment goals to be the induction and maintenance of remission; ${ }^{70,72,74}$ this infers that treatment failure is an inability to meet these goals. The CAG guidelines define 5-ASA treatment failure to be the "inability of the patient to achieve and maintain complete corticosteroid-free remission despite optimal treatment with oral, rectal, or combination 5-ASA therapy." ${ }^{m 71}$ The opinion of the panel was that the ability to achieve and maintain remission are distinct occurrences and so they are presented as separate statements.

Statement 15: An increased bowel frequency above normal (for that individual) and the presence of rectal bleeding on consecutive days should be considered to be suggestive of a flare (grade B) (strongly agreed 54.6\% agreed 36.4\%; disagreed 9.0\%: CONSENSUS REACHED)

Where defined, guidelines define remission as a normal stool frequency $(\leq 3 /$ day $)$ with no blood in stool and potential confirmation of mucosal healing. ${ }^{69,71}$ The guidelines define relapse/flare as the opposite of being in remission. ${ }^{69,71}$ The consensus was that remission is defined as a normal bowel frequency ( $\leq 3 /$ day), absence of rectal bleeding and normal mucosal appearance on endoscopy, with relapse/flare defined as the opposite. There is little guidance available on the timescale over which symptoms need to be present for a flare to be determined. It was the opinion of the expert panel that these changes need to be present on consecutive days in order for a UC flare to be the most likely cause.

The differentiation between a UC flare and Clostridium difficile infection can be challenging as symptoms can be identical. ${ }^{76,77}$ UC patients are at an increased risk for $C$. difficile infection, ${ }^{76-78}$ both inside and outside the hospital setting. ${ }^{78}$ However, the rate of C. difficile in patients with UC flares is still quite low; around $5 \%$ of UC patients with a flare test positive for C. difficile. ${ }^{79,80}$ C. difficile 
infection risk is greatest in patients with recent hospitalization, recent antibiotic use or immunosuppression ${ }^{76,78}$ The use of iSTART (i Support Therapy-Access to Rapid Treatment) should be at the treating physician's discretion, and only in patients at a low risk of C. difficile infection.

Statement 16: Factors that predict 5-ASA treatment failure include: disease extent greater than proctitis (grade C), lack of normalization of fecal calprotectin (grade B), lack of mucosal healing (grade B) and EIMs (grade C) (strongly agreed 55.6\%; agreed 33.3\%: disagreed 11.1\%: CONSENSUS REACHED)

The evidence regarding disease extent as a risk factor for treatment failure is mixed. However, a majority of studies showed a higher risk of relapse with a greater disease extent; particularly when considering proctitis versus a greater extent. ${ }^{55,58,81}$ Fecal calprotectin (FC) levels have been identified as a potential predictor of relapse, and a meta-analysis found that FC had an overall sensitivity of $77 \%$ and a specificity of $71 \%$ as a predictive factor for relapse..$^{82} \mathrm{~A}$ variety of cutoff values have been used to define increased risk, varying from $50 \mathrm{mg} / \mathrm{L}$ to $200 \mu \mathrm{g} / \mathrm{g}{ }^{83,84}$ The expert panel was of the opinion that a lack of normalization of FC levels is the best measure to use as a risk factor for 5-ASA treatment failure. There is strong evidence that absence of mucosal healing is linked to 5-ASA treatment failure and an increased risk/rate of relapse. ${ }^{1785-87}$ The presence of EIMs has been found to be associated with a higher rate of 5-ASA failure ${ }^{55,81,88}$ The ECCO guidelines describe the presence of EIMs as a possible risk factor for relapse in patients with quiescent disease. $^{70}$

Statement 17: Low educational attainment (grade D), formerly smoking (grade D), unmarried status (grade D), stress (grade D) and a low-fiber diet (grade D) may predict increased rate of 5-ASA treatment failure (strongly agreed $27.4 \%$; agreed $63.6 \%$; disagreed $9.0 \%$ : CONSENSUS REACHED)

A range of other potential risk factors for 5-ASA treatment failure have been identified, but all have a lack of supporting evidence. Possible risk factors include a lack education above high school level, ${ }^{89}$ former smokers,${ }^{90}$ and being unmarried.$^{91,92}$ ECCO guidelines describe multiple possible risk factors for relapse in patients with quiescent disease including stress and low-fiber diet. ${ }^{70}$ Nonadherence is a well-established risk factor for 5-ASA failure, ${ }^{70}$ but is hard to predict and has links to many of the other risk factors described here.

\section{Second-Line Treatment and Self-Led Patient Assessment}

Statement 18: Corticosteroids are the recommended first-line treatment for patients with mild-to-moderate UC who show a lack of response to optimized 5-ASA therapy (grade $\mathrm{A}-\mathrm{C}$, depending on disease extent) (strongly agreed 54.5\%; agreed 45.5\%; disagreed 0.0\%: CONSENSUS REACHED)

Guidelines for patients with mild-to-moderate UC that do not respond sufficiently to optimized 5-ASA therapy are generally consistent, recommending corticosteroids as oral or rectal therapies (dependent on disease extent) ${ }^{70,71,74,75}$

Statement 19: Oral budesonide $M M{ }^{\circledR}$ is an effective treatment option for patients failing to respond to optimized 5-ASA therapy and an alternative for patients intolerant to 5-ASA (grade A) (strongly agreed 70.0\%; agreed 30.0\%; disagreed 0.0\%: CONSENSUS REACHED)

A Cochrane analysis of budesonide $\mathrm{MMX}^{\circledR}$ has shown that it can induce remission in $15 \%$ of patients versus $9 \%$ for placebo (RR, 2.25; 95\% CI, 1.50-3.39), ${ }^{93}$ with no difference in adverse events (RR, 0.85; 95\% CI, 0.53-1.38). ${ }^{93}$ Remission rates were low compared to other UC therapies due to the CORE I and CORE II studies using a strict definition of "combined clinical and endoscopic remission," defined as a normal bowel frequency with no rectal bleeding and endoscopic remission based on a full colonoscopy. ${ }^{94}$ 
Statement 20: Validated patient-reported outcome measures are required for patient self-assessment of flares (grade C); the PRUCSI, PRO2 and $\mathrm{mHI}-\mathrm{UC}$ are such measures that have strong discriminatory power for flares (grade $\mathrm{C}$ ) (strongly agreed $80.0 \%$; agreed $20.0 \%$; disagreed $0.0 \%$ : CONSENSUS REACHED)

Statement 21: Patient-initiated treatment allows for a rapid response to flares that can reduce flare length and healthcare utilization (grade C)

(strongly agreed 63.6\%; agreed 36.4\%; disagreed 0.0\%: CONSENSUS REACHED)

The evidence supporting these statements is included with the main manuscript.

\section{REFERENCES}

1. Molodecky NA, Soon IS, Rabi DM, et al. Increasing incidence and prevalence of the inflammatory bowel diseases with time, based on systematic review. Gastroenterology 2012;142:46-54.

2. M'Koma AE. Inflammatory bowel disease: an expanding global health problem. Clin Med Insights Gastroenterol 2013;6:33-47.

3. Prideaux L, Kamm MA, De Cruz PP, Chan FK, Ng SC. Inflammatory bowel disease in Asia: a systematic review. J Gastroenterol Hepatol 2012; 27:1266-1280.

4. Burisch J, Pedersen N, Čuković-Čavka S, et al. East-West gradient in the incidence of inflammatory bowel disease in Europe: the ECCO-EpiCom inception cohort. Gut 2014;63:588-597.

5. Benchimol EI, Manuel DG, Guttmann A, et al. Changing age demographics of inflammatory bowel disease in Ontario, Canada: a populationbased cohort study of epidemiology trends. Inflamm Bowel Dis 2014;20:1761-1769.

6. Bitton A, Vutcovici M, Patenaude V, Sewitch M, Suissa S, Brassard P. Epidemiology of inflammatory bowel disease in Québec: recent trends. Inflamm Bowel Dis 2014;20:1770-1776.

7. Ng SC, Tang W, Ching JY, et al. Incidence and phenotype of inflammatory bowel disease based on results from the Asia-pacific Crohn's and colitis epidemiology study. Gastroenterology 2013;145:158-165.

8. Buenavida G, Casañias A, Vásquez C, et al. Incidence of inflammatory bowel disease in five geographical areas of Uruguay in the biennial 2007-2008. Acta Gastroenterol Latinoam 2011;41:281-287.

9. Lucendo AJ, Hervías D, Roncero Ó, et al. Epidemiology and temporal trends (2000-2012) of inflammatory bowel disease in adult patients in a central region of Spain. Eur J Gastroenterol Hepatol 2014;26:1399-1407.

10. Iyngkaran G, Hunt J, Thambimuthu T, et al. Inflammatory bowel disease is prevalent in Australia but rare in indigenous Australians. J Gastroenterol Hepatol 2015;30:16-17.

11. Ng SC, Leung WK, Shi HY, et al. Epidemiology of inflammatory bowel disease from 1981 to 2014: results from a territory-wide populationbased registry in Hong Kong. Inflamm Bowel Dis 2016;22:1954-1960.

12. Chuang CH, Lin SH, Chen CY, Sheu BS, Kao AW, Wang JD. Increasing incidence and lifetime risk of inflammatory bowel disease in Taiwan: a nationwide study in a low-endemic area 1998-2010. Inflamm Bowel Dis 2013;19:2815-2819.

13. Lok KH, Hung HG, $\mathrm{Ng} \mathrm{CH}$, et al. Epidemiology and clinical characteristics of ulcerative colitis in Chinese population: experience from a single center in Hong Kong. J Gastroenterol Hepatol 2008;23:406-410.

14. Nuij VJ, Zelinkova Z, Rijk MC, et al. Phenotype of inflammatory bowel disease at diagnosis in the Netherlands: a population-based inception cohort study (the Delta Cohort). Inflamm Bowel Dis 2013;19:2215-2222.

15. Yazdanbod A, Farzaneh E, Pourfarzi F, et al. Epidemiologic profile and clinical characteristics of ulcerative colitis in northwest of Iran: a 10year review. Trop Gastroenterol 2010;31:308-311.

16. Gheorghe C, Pascu O, Gheorghe L, et al. Epidemiology of inflammatory bowel disease in adults who refer to gastroenterology care in Romania: a multicentre study. Eur J Gastroenterol Hepatol 2004;16:1153-1159.

17. Ling KL, Ooi CJ, Luman W, Cheong WK, Choen FS, Ng HS. Clinical characteristics of ulcerative colitis in Singapore, a multiracial city-state. J Clin Gastroenterol 2002;35:144-148.

18. Niriella MA, De Silva AP, Dayaratne AH, et al. Prevalence of inflammatory bowel disease in two districts of Sri Lanka: a hospital based survey. BMC Gastroenterol 2010;10:32. 
19. Wang Y, Ouyang Q; APDW 2004 Chinese IBD working group. Ulcerative colitis in China: retrospective analysis of 3100 hospitalized patients. J Gastroenterol Hepatol 2007;22:1450-1455.

20. Ray G. Inflammatory bowel disease in India: changing paradigms. Int J Colorectal Dis 2011;26:635-644.

21. Portela F, Magro F, Lago P, et al. Ulcerative colitis in a Southern European country: a national perspective. Inflamm Bowel Dis 2010;16:822-829.

22. Sjöberg D, Holmström T, Larsson M, et al. Incidence and natural history of ulcerative colitis in the Uppsala Region of Sweden 2005-2009: results from the IBD cohort of the Uppsala Region (ICURE). J Crohns Colitis 2013;7:e351-e357.

23. Farrell D, McCarthy G, Savage E. Self-reported symptom burden in individuals with inflammatory bowel disease. J Crohns Colitis 2016;10: 315-322.

24. Bager P, Befrits R, Wikman O, et al. Fatigue in out-patients with inflammatory bowel disease is common and multifactorial. Aliment Pharmacol Ther 2012;35:133-141.

25. Graff LA, Clara I, Walker JR, et al. Changes in fatigue over 2 years are associated with activity of inflammatory bowel disease and psychological factors. Clin Gastroenterol Hepatol 2013;11:1140-1146.

26. Coates MD, Lahoti M, Binion DG, Szigethy EM, Regueiro MD, Bielefeldt K. Abdominal pain in ulcerative colitis. Inflamm Bowel Dis 2013;19: $2207-2214$.

27. Vavricka SR, Brun L, Ballabeni P, et al. Frequency and risk factors for extraintestinal manifestations in the Swiss inflammatory bowel disease cohort. Am J Gastroenterol 2011;106:110-119.

28. Norton C, Dibley LB, Bassett P. Faecal incontinence in inflammatory bowel disease: associations and effect on quality of life. J Crohns Colitis 2013;7:e302-e311.

29. Panara AJ, Yarur AJ, Rieders B, et al. The incidence and risk factors for developing depression after being diagnosed with inflammatory bowel disease: a cohort study. Aliment Pharmacol Ther 2014;39:802-810.

30. Bryant RV, van Langenberg DR, Holtmann GJ, Andrews JM. Functional gastrointestinal disorders in inflammatory bowel disease: impact on quality of life and psychological status. J Gastroenterol Hepatol 2011;26:916-923.

31. Tabatabaeian M, Afshar H, Roohafza HR, et al. Psychological status in Iranian patients with ulcerative colitis and its relation to disease activity and quality of life. J Res Med Sci 2015;20:577-584.

32. Ananthakrishnan AN, Long MD, Martin CF, Sandler RS, Kappelman MD. Sleep disturbance and risk of active disease in patients with Crohn's disease and ulcerative colitis. Clin Gastroenterol Hepatol 2013;11:965-971.

33. Graff LA, Vincent N, Walker JR, et al. A population-based study of fatigue and sleep difficulties in inflammatory bowel disease. Inflamm Bowel Dis 2011;17:1882-1889.

34. Rubin DT, Dubinsky MC, Panaccione R, et al. The impact of ulcerative colitis on patients' lives compared to other chronic diseases: a patient survey. Dig Dis Sci 2010;55:1044-1052.

35. Huppertz-Hauss G, Lie Høivik M, Jelsness-Jørgensen LP, et al. Health-related quality of life in patients with inflammatory bowel disease 20 years after diagnosis: results from the IBSEN Study. Inflamm Bowel Dis 2016;22:1679-1687.

36. Theede K, Kiszka-Kanowitz M, Nordgaard-Lassen I, Mertz Nielsen A. The impact of endoscopic inflammation and mucosal healing on healthrelated quality of life in ulcerative colitis patients. J Crohns Colitis 2015;9:625-632.

37. Alcalá MJ, Casellas F, Fontanet G, Prieto L, Malagelada JR. Shortened questionnaire on quality of life for inflammatory bowel disease. Inflamm Bowel Dis 2004;10:383-391.

38. Romberg-Camps MJ, Bol Y, Dagnelie PC, et al. Fatigue and health-related quality of life in inflammatory bowel disease: results from a population-based study in the Netherlands: the IBD-South Limburg cohort. Inflamm Bowel Dis 2010;16:2137-2147.

39. Haapamäki J, Roine RP, Sintonen H, Turunen U, Färkkilä MA, Arkkila PE. Health-related quality of life in inflammatory bowel disease measured with the generic 15D instrument. Qual Life Res 2010;19:919-928.

40. Tabibian A, Tabibian JH, Beckman LJ, Raffals LL, Papadakis KA, Kane SV. Predictors of health-related quality of life and adherence in Crohn's disease and ulcerative colitis: implications for clinical management. Dig Dis Sci 2015;60:1366-1374.

41. Bernklev T, Jahnsen J, Schulz T, et al. Course of disease, drug treatment and health-related quality of life in patients with inflammatory bowel disease 5 years after initial diagnosis. Eur J Gastroenterol Hepatol 2005;17:1037-1045.

42. Stark RG, Reitmeir P, Leidl R, König HH. Validity, reliability, and responsiveness of the EQ-5D in inflammatory bowel disease in Germany. Inflamm Bowel Dis 2010;16:42-51.

43. Gibson PR, Vaizey C, Black CM, et al. Relationship between disease severity and quality of life and assessment of health care utilization and cost for ulcerative colitis in Australia: a cross-sectional, observational study. J Crohns Colitis 2014;8:598-606. 


\section{INTESTINAL RESEARCH}

44. Castillo-Cejas MD, Robles V, Borruel N, et al. Questionnaries for measuring fatigue and its impact on health perception in inflammatory bowel disease. Rev Esp Enferm Dig 2013;105:144-153.

45. Bodger K, Yen L, Szende A, et al. Medical resource utilization and associated costs in patients with ulcerative colitis in the UK: a chart review analysis. Eur J Gastroenterol Hepatol 2014;26:213-221.

46. de Boer AG, Sprangers MA, Bartelsman JF, de Haes HC. Predictors of health care utilization in patients with inflammatory bowel disease: a longitudinal study. Eur J Gastroenterol Hepatol 1998;10:783-789.

47. Sulz MC, Siebert U, Arvandi M, et al. Predictors for hospitalization and outpatient visits in patients with inflammatory bowel disease: results from the Swiss Inflammatory Bowel Disease Cohort Study. Eur J Gastroenterol Hepatol 2013;25:790-797.

48. Bassi A, Dodd S, Williamson P, Bodger K. Cost of illness of inflammatory bowel disease in the UK: a single centre retrospective study. Gut 2004;53:1471-1478.

49. Siebert U, Wurm J, Gothe RM, et al. Predictors of temporary and permanent work disability in patients with inflammatory bowel disease: results of the swiss inflammatory bowel disease cohort study. Inflamm Bowel Dis 2013;19:847-855.

50. Ramos A, Calvet X, Sicilia B, et al. IBD-related work disability in the community: prevalence, severity and predictive factors. A cross-sectional study. United European Gastroenterol J 2015;3:335-342.

51. Burisch J, Pedersen N, Cukovic-Cavka S, et al. Initial disease course and treatment in an inflammatory bowel disease inception cohort in Europe: the ECCO-EpiCom cohort. Inflamm Bowel Dis 2014;20:36-46.

52. Rocchi A, Benchimol EI, Bernstein CN, et al. Inflammatory bowel disease: a Canadian burden of illness review. Can J Gastroenterol 2012;26: 811-817.

53. Hilmi I, Singh R, Ganesananthan S, et al. Demography and clinical course of ulcerative colitis in a multiracial Asian population: a nationwide study from Malaysia. J Dig Dis 2009;10:15-20.

54. Jonefjäll B, Strid H, Ohman L, Svedlund J, Bergstedt A, Simren M. Characterization of IBS-like symptoms in patients with ulcerative colitis in clinical remission. Neurogastroenterol Motil 2013;25:756-e578.

55. Cravo ML, Ferreira PA, Sousa P, et al. IL23R polymorphisms influence phenotype and response to therapy in patients with ulcerative colitis. Eur J Gastroenterol Hepatol 2014;26:26-32.

56. Bresci G, Parisi G, Capria A. Duration of remission and long-term prognosis according to the extent of disease in patients with ulcerative colitis on continuous mesalamine treatment. Colorectal Dis 2008;10:814-817.

57. Bresci G, Parisi G, Bertoni M, Capria A. Long-term maintenance treatment in ulcerative colitis: a 10-year follow-up. Dig Liver Dis 2002;34:419423.

58. Lee HJ, Jung ES, Lee JH, et al. Long-term clinical outcomes and factors predictive of relapse after 5-aminosalicylate or sulfasalazine therapy in patients with mild-to-moderate ulcerative colitis. Hepatogastroenterology 2012;59:1415-1420.

59. Höie O, Wolters F, Riis L, et al. Ulcerative colitis: patient characteristics may predict 10-yr disease recurrence in a European-wide populationbased cohort. Am J Gastroenterol 2007;102:1692-1701.

60. Solberg IC, Lygren I, Jahnsen J, et al. Clinical course during the first 10 years of ulcerative colitis: results from a population-based inception cohort (IBSEN Study). Scand J Gastroenterol 2009;44:431-440.

61. Romberg-Camps MJ, Dagnelie PC, Kester AD, et al. Influence of phenotype at diagnosis and of other potential prognostic factors on the course of inflammatory bowel disease. Am J Gastroenterol 2009;104:371-383.

62. Wang Y, Parker CE, Bhanji T, Feagan BG, MacDonald JK. Oral 5-aminosalicylic acid for induction of remission in ulcerative colitis. Cochrane Database Syst Rev 2016;4:CD000543. doi: 10.1002/14651858.CD000543.pub4.

63. Sandborn WJ, Travis S, Moro L, et al. Once-daily budesonide MMX ${ }^{\circledR}$ extended-release tablets induce remission in patients with mild to moderate ulcerative colitis: results from the CORE I study. Gastroenterology 2012;143:1218-1226.

64. Travis SP, Danese S, Kupcinskas L, et al. Once-daily budesonide MMX in active, mild-to-moderate ulcerative colitis: results from the randomised CORE II study. Gut 2014;63:433-441.

65. Daryani NE, Bashashati M, Aram S, et al. Pattern of relapses in Iranian patients with ulcerative colitis: a prospective study. J Gastrointestin Liver Dis 2006;15:355-358.

66. Radhakrishnan S, Zubaidi G, Daniel M, Sachdev GK, Mohan AN. Ulcerative colitis in Oman: a prospective study of the incidence and disease pattern from 1987 to 1994. Digestion 1997;58:266-270.

67. Kim JH, Cheon JH, Park Y, et al. Effect of mucosal healing (Mayo 0) on clinical relapse in patients with ulcerative colitis in clinical remission. Scand J Gastroenterol 2016;51:1069-1074. 
68. Schreiber S, Panés J, Louis E, Holley D, Buch M, Paridaens K. Perception gaps between patients with ulcerative colitis and healthcare professionals: an online survey. BMC Gastroenterol 2012;12:108.

69. Magro F, Gionchetti P, Eliakim R, et al. Part 1: definitions, diagnosis, extra-intestinal manifestations, pregnancy, cancer surveillance, surgery, and ileo-anal pouch disorders. J Crohns Colitis 2017;11:649-670.

70. Harbord M, Eliakim R, Bettenworth D, et al. Third European evidence-based consensus on diagnosis and management of ulcerative colitis. Part 2: current management. J Crohns Colitis 2017;11:769-784.

71. Bressler B, Marshall JK, Bernstein CN, et al. Clinical practice guidelines for the medical management of nonhospitalized ulcerative colitis: the Toronto consensus. Gastroenterology 2015;148:1035-1058.

72. Bernstein C, Eliakim A, Fedail S, et al. Inflammatory bowel disease: World Gastroenterology Organisation global guidelines. Milwaukee: World Gastroenterology Organisation, 2015.

73. American Gastroenterology Association. Identification, assessment and initial medical treatment of ulcerative colitis: clinical care pathway. Bethesda: American Gastroenterology Association, 2015.

74. Kornbluth A, Sachar DB; Practice Parameters Committee of the American College of Gastroenterology. Ulcerative colitis practice guidelines in adults: American College of Gastroenterology, Practice Parameters Committee. Am J Gastroenterol 2010;105:501-523.

75. Yamamoto-Furusho JK, Bosques-Padilla F, de-Paula J, et al. Diagnosis and treatment of inflammatory bowel disease: first Latin American Consensus of the Pan American Crohn's and Colitis Organisation. Rev Gastroenterol Mex 2017;82:46-84.

76. Nitzan O, Elias M, Chazan B, Raz R, Saliba W. Clostridium difficile and inflammatory bowel disease: role in pathogenesis and implications in treatment. World J Gastroenterol 2013;19:7577-7585.

77. Khanna S, Shin A, Kelly CP. Management of Clostridium difficile infection in inflammatory bowel disease: expert review from the clinical practice updates committee of the AGA institute. Clin Gastroenterol Hepatol 2017;15:166-174.

78. Navaneethan U, Venkatesh PG, Shen B. Clostridium difficile infection and inflammatory bowel disease: understanding the evolving relationship. World J Gastroenterol 2010;16:4892-4904.

79. Masclee GM, Penders J, Jonkers DM, Wolffs PF, Pierik MJ. Is Clostridium difficile associated with relapse of inflammatory bowel disease? Results from a retrospective and prospective cohort study in the Netherlands. Inflamm Bowel Dis 2013;19:2125-2131.

80. Mylonaki M, Langmead L, Pantes A, Johnson F, Rampton DS. Enteric infection in relapse of inflammatory bowel disease: importance of microbiological examination of stool. Eur J Gastroenterol Hepatol 2004;16:775-778.

81. Safroneeva E, Vavricka SR, Fournier N, Straumann A, Rogler G, Schoepfer AM. Prevalence and risk factors for therapy escalation in ulcerative colitis in the Swiss IBD cohort study. Inflamm Bowel Dis 2015;21:1348-1358.

82. Mao R, Xiao YL, Gao X, et al. Fecal calprotectin in predicting relapse of inflammatory bowel diseases: a meta-analysis of prospective studies. Inflamm Bowel Dis 2012;18:1894-1899.

83. Osterman MT, Aberra FN, Cross R, et al. Mesalamine dose escalation reduces fecal calprotectin in patients with quiescent ulcerative colitis. Clin Gastroenterol Hepatol 2014;12:1887-1893.

84. Tibble JA, Sigthorsson G, Bridger S, Fagerhol MK, Bjarnason I. Surrogate markers of intestinal inflammation are predictive of relapse in patients with inflammatory bowel disease. Gastroenterology 2000;119:15-22.

85. Meucci G, Fasoli R, Saibeni S, et al. Prognostic significance of endoscopic remission in patients with active ulcerative colitis treated with oral and topical mesalazine: a prospective, multicenter study. Inflamm Bowel Dis 2012;18:1006-1010.

86. Zakko SF, Gordon GL, Murthy U, et al. Once-daily mesalamine granules for maintaining remission of ulcerative colitis: pooled analysis of efficacy, safety, and prognostic factors. Postgrad Med 2016;128:273-281.

87. Yokoyama K, Kobayashi K, Mukae M, Sada M, Koizumi W. Relation between mucosal healing and long-term outcomes in patients with ulcerative colitis. Gastroenterol 2013;144(5 Suppl 1):S-427.

88. Marakhouski Y, Fixa B, Holomán J, et al. A double-blind dose-escalating trial comparing novel mesalazine pellets with mesalazine tablets in active ulcerative colitis. Aliment Pharmacol Ther 2005;21:133-140.

89. Kawakami A, Tanaka M, Nishigaki M, et al. Relationship between non-adherence to aminosalicylate medication and the risk of clinical relapse among Japanese patients with ulcerative colitis in clinical remission: a prospective cohort study. J Gastroenterol 2013;48:1006-1015.

90. Hawthorne AB, Stenson R, Gillespie D, et al. One-year investigator-blind randomized multicenter trial comparing Asacol $2.4 \mathrm{~g}$ once daily with $800 \mathrm{mg}$ three times daily for maintenance of remission in ulcerative colitis. Inflamm Bowel Dis 2012;18:1885-1893.

91. Khan N, Abbas AM, Bazzano LA, Koleva YN, Krousel-Wood M. Long-term oral mesalazine adherence and the risk of disease flare in ulcerative colitis: nationwide 10-year retrospective cohort from the veterans affairs healthcare system. Aliment Pharmacol Ther 2012;36:755-764. 
92. Khan N, Abbas AM, Koleva YN, Bazzano LA. Long-term mesalamine maintenance in ulcerative colitis: which is more important? Adherence or daily dose. Inflamm Bowel Dis 2013;19:1123-1129.

93. Sherlock ME, MacDonald JK, Griffiths AM, Steinhart AH, Seow CH. Oral budesonide for induction of remission in ulcerative colitis. Cochrane Database Syst Rev 2015:CD007698. doi: 10.1002/14651858.CD007698.pub3.

94. Sandborn WJ, Danese S, D'Haens G, et al. Induction of clinical and colonoscopic remission of mild-to-moderate ulcerative colitis with budesonide MMX 9 mg: pooled analysis of two phase 3 studies. Aliment Pharmacol Ther 2015;41:409-418. 